\title{
Alterações dentoesqueléticas e do perfil facial em pacientes tratados ortodonticamente com extração de quatro primeiros pré-molares
}

\author{
Giovani Fidelis de Oliveira*, Marcio Rodrigues de Almeida**, Renato Rodrigues de Almeida***,

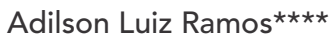

\begin{abstract}
Resumo
Objetivo e Metodologia: o presente estudo prospectivo objetivou analisar cefalometricamente as alterações dentoesqueléticas e do perfil tegumentar após o tratamento ortodôntico de casos com extrações dos quatro primeiros pré-molares. A amostra consistiu de 30 jovens de ambos os gêneros, com idade média inicial de 12 anos e 4 meses, portadores de má oclusão Classe II, $1^{\text {a }}$ divisão de Angle. As principais referências do trabalho concentram-se nas grandezas cefalométricas dos incisivos superiores e inferiores em relação às coordenadas vertical e horizontal, bem como às alterações dos lábios e ângulo nasolabial pré e pós-tratamento. Resultados: os resultados demonstraram que houve retração média dos incisivos superiores de $3,4 \mathrm{~mm}$ e dos inferiores de $1,8 \mathrm{~mm}$. O ponto A sofreu discreta alteração devido à retração dos incisivos superiores, discriminada pela diminuição média do ângulo SNA (1,7 graus). Houve melhora na relação maxilomandibular, demonstrada pela diminuição das grandezas Wits e ANB. Não houve diferenças estaticamente significantes para as grandezas cefalométricas SN.GoGn e SN.GoMe, embora a altura facial ântero-inferior tenha aumentado, em decorrência do crescimento craniofacial normal. Observou-se que para cada $1 \mathrm{~mm}$ de retração dos incisivos superiores, o ângulo nasolabial aumentou significativamente 2,8 graus, muito embora tenha ocorrido grande variabilidade individual. Conclusão: conclui-se que o tratamento com extrações de primeiros pré-molares sobre o perfil facial não se relaciona obrigatoriamente com o "achatamento" do mesmo, sendo também dependente da quantidade de apinhamento no pré-tratamento. As alterações foram decorrentes do crescimento e desenvolvimento facial, da quantidade de retração e da efetiva ancoragem durante a retração dos incisivos superiores e inferiores.
\end{abstract}

Palavras-chave: Extração de pré-molares. Perfil facial. Tratamento ortodôntico fixo.

* Especialista em Ortodontia e Ortopedia Facial pela Faculdade de Odontologia de Lins da Universidade Metodista de Piracicaba-UNIMEP. ** Pós-Doutorado em Ortodontia pela Faculdade de Odontologia de Bauru-USP e Coordenador do Curso de Especialização da Faculdade de Odontologia de Lins da Universidade Metodista de Piracicaba-UNIMEP.

** Professor Associado do Departamento de Ortodontia e Odontopediatria da Faculdade de Odontologia de Bauru-USP. Titular da Faculdade de Odontologia de Lins - UNIMEP.

**** Mestre em Ortodontia pela Faculdade de Odontologia de Bauru-USP. Doutor pela UNESP-Araraquara e Professor Coordenador do Curso de Especialização da Universidade Estadual de Maringá-PR. 


\section{INTRODUÇÃO E REVISÃO DE LITERATURA}

Por muitos anos, o perfil facial tegumentar em pacientes tratados ortodonticamente vem sendo estudado com o objetivo de alcançar a harmonia, relacionada a um correto posicionamento dentário. No passado, a estética do perfil facial foi descrita muito subjetivamente e, de acordo com Angle ${ }^{1}$, o conceito de beleza aproximar-se-ia da figura do deus grego Apolo de Belvedere. Porém, os modelos de beleza sofreram alterações, possivelmente devido à miscigenação de raças, à mídia globalizada, aos costumes, à religião e à época; tornando-se mais protrusos, ao invés de traços retos como dos gregos.

O revestimento do tecido mole possui as formas mais variadas, como tonicidade, espessura muscular e diferentes conformações das bases ósseas, o que multiplica as variáveis que afetam a relação entre retração dentária e o movimento dos lábios.

As variáveis envolvidas no tratamento ortodôntico mostram que uma finalização que contenha beleza, harmonia facial e oclusão adequada, com o máximo de estabilidade, não se apresenta como tarefa fácil, mesmo aos mais capacitados ortodontistas. A correção da má oclusão com alteração na posição dos dentes, principalmente dos incisivos, levando-se em consideração idade, tipo facial, tônus e padrão muscular, resulta freqüentemente em uma estética mais agradável, definida como um estado de harmonia e equilíbrio das proporções faciais determinadas pelas estruturas esqueléticas, pelos dentes e tecidos moles. Para tanto, o planejamento ortodôntico requer atenção.

Bowman e Johnston $\mathrm{Jr}^{7}$ relataram que o medo de causar um achatamento no perfil, resultante de extrações de pré-molares, originou-se em grande parte de processos isolados e relatórios de resultados selecionados.

Lamentavelmente, a alegação de que as técnicas ortodônticas tradicionais geralmente "achatavam” o perfil facial não são atualmente válidas ${ }^{7,26,30}$. Em média, o efeito das extrações de pré-molares no perfil facial é de aproximadamente $2 \mathrm{~mm}$ de retrusão, embora seja uma mudança clinicamente discernível, ela é suficiente para melhorar o perfil em casos de protrusão, sendo uma mudança geralmente bem aceita, pois os próprios pacientes buscam este resultado quando procuram o tratamento. Na maioria dos casos, o "achatamento" em excesso é uma conseqüência de um diagnóstico e plano de tratamento incorretos.

A correção da má oclusão promove uma melhora na função, nas relações estéticas e no embelezamento das linhas faciais. Case ${ }^{11}$ já mencionava a importância da estética facial, declarando que a linha facial deveria ser um guia fundamental na determinação dos objetivos e dos procedimentos do tratamento, além de defender extrações em casos de biprotrusões, para retrair os lábios projetados.

Zierhut et al. ${ }^{30}$ compararam a alteração do perfil facial, imediato ao pós-tratamento e um longo período pós-contenção em pacientes com má oclusão Classe II, $1^{a}$ divisão, tratados com e sem extração de quatro primeiros pré-molares. Observaram que o perfil facial tegumentar dos grupos com e sem extrações foram semelhantes, tanto imediatamente após o tratamento quanto após um longo período de contenção. Também relataram um progressivo "achatamento" do perfil facial em ambos os grupos, decorrente das mudanças na maturação associada com contínuo crescimento mandibular e desenvolvimento nasal, sendo este fato não influenciado pela remoção dos dentes. Identificaram, ainda, que a posição dos lábios após um longo período de contenção foi mais retrusa do que o ideal sugerido por Ricketts e Steiner, mas foi similar aos valores normais de adultos não tratados na mesma faixa etária.

Ramos $^{27}$ estudou casos clínicos, com extrações de somente dois pré-molares superiores, de pacientes com e sem selamento labial, empregando implantes na maxila e na mandibula para auxiliar as sobreposições. Observou que houve uma correlação entre a retração dos incisivos e o lábio superior, em relação ao movimento do ponto cervical do incisivo superior. Ainda descreveu que os ângulos labial 
e nasolabial apresentaram baixa previsibilidade de comportamento, embora com a nítida tendência de aumentar em função da retração dos incisivos.

Bascifiti ${ }^{3}$ estudou 87 pacientes com má oclusão Classe II, divisão 1, e Classe I tratados com e sem extração de pré-molares. A telerradiografia lateral revelou não haver diferença significante entre os pacientes tratados com ou sem extração de pré-molares em ambos os grupos. Apesar do grupo sem extração ter apresentado significante protrusão dos incisivos, nenhuma outra alteração foi verificada na posição do lábio ou perfil. Os autores concluíram que o simples fato de se ter extraído dentes não significa um perfil mais retruso. Relataram que a presença de um grande apinhamento no pré-tratamento, a maior espessura do tecido mole e fatores relacionados com a ancoragem influenciam na alteração do perfil.

O presente estudo prospectivo buscou avaliar as alterações dentoesqueléticas e do perfil facial em casos tratados com extrações de quatro prémolares, com adequada indicação para tal, utilizando aparelho fixo com mecânica Straight-wire, numa amostra de jovens brasileiros portadores de Classe II divisão 1 .

\section{MATERIAL E MÉTODOS}

A amostra deste estudo prospectivo foi composta de 30 pacientes ( 16 jovens do gênero feminino e 14 do masculino) com má oclusão de Classe II, $1^{\text {a }}$ divisão de Angle, tratados consecutivamente com aparelhagem fixa e extração de quatro primeiros pré-molares, durante o ano de 2000 a 2003, no Curso de Especialização em Ortodontia da UNIMEP/Lins. A idade média inicial dos pacientes foi de 12 anos e 4 meses e a idade média final de 15 anos e 5 meses. O período médio de tratamento foi de 3 anos e 1 mês.

Os pacientes selecionados apresentavam as seguintes características:

1) Todos os pacientes apresentaram má oclusão de Classe II, $1^{\text {a }}$ divisão de Angle, constatada por meio de fichas clínicas e modelos de estudo;
2) ângulo ANB médio inicial maior que 5 graus; 3) WITS médio inicial maior que $7 \mathrm{~mm}$; 4) ausência de agenesias ou mutilações nos arcos dentários superior e inferior; 5) apinhamento médio superior e inferior de $5 \mathrm{~mm}$; 6) todos foram tratados com aparelho fixo pela mecânica Straight-Wire prescrição Roth canaleta 0,022 " x 0,028 ", utilizando como ancoragem no arco superior a Barra Transpalatina - BTP e o Aparelho Extrabucal AEB no período noturno com média de força de 400 gramas de cada lado; 7) o método de retração utilizado foi o de deslize - elástico em cadeia ou peixinho, utilizando arco retangular de aço 0,019" x 0,025 ". A sequiência clínica dos arcos foi 0,014 ", 0,016 " e 0,018 " de nitinol, 0,020 " de aço, 0,019" x 0,025 " de nitinol e finalmente o arco retangular de aço $0,019 "$ x 0,025 ".

Foram obtidas 30 telerradiografias em norma lateral ao início e 30 ao término do tratamento, totalizando 60 telerradiografias.

\section{Radiografias cefalométricas}

As telerradiografias, em norma lateral, foram obtidas por um aparelho de raios X Yoshidamodelo Panoura, com os fatores de exposição regulados para $90 \mathrm{Kvp}$ e $15 \mathrm{~mA}$. O posicionamento da cabeça, orientado pelo cefalostato, mantinha o plano sagital mediano do paciente perpendicular e a linha infraorbitária paralela, ambos em relação ao solo. Os pacientes foram orientados para que os lábios permanecessem em repouso, manipulandose a mandíbula para a obtenção de posição cêntrica, sendo mantidos os dentes em oclusão. Foram utilizados os filmes da marca KODAK, devidamente identificados, de $18 \mathrm{~cm}$ x $24 \mathrm{~cm}$ com écran intensificador de média intensidade, marca e modelo Toshiba EU 5A0335.

\section{Cefalograma}

Cada película radiográfica recebeu uma folha de papel de acetato transparente da marca GAC de tamanho 8" x 10 " e espessura de 0,003 ". Os cefalogramas foram traçados manualmente, em sala 
escurecida, por um único operador. Em seguida, os pontos cefalométricos foram demarcados com lapiseira Pentel provida de grafite HP de $0,5 \mathrm{~mm}$. Ainda foram traçadas as linhas e os planos de referência para a obtenção das medidas lineares (em milímetros) e angulares (em graus).

Os pontos clássicos cefalométricos, bem como as linhas e planos de orientação estão expostos na figura 1 .

\section{Sobreposições parciais da maxila e da man- díbula}

Para obtenção da alteração do ponto cervical do incisivo superior, foi utilizada a sobreposição parcial da maxila, que utilizou como referência o plano ENA-ENP. Referências cartesianas foram baseadas em uma linha traçada 7 graus em relação à linha $\mathrm{SN}\left(\mathrm{SN}-7^{\circ}\right)$, bem como o eixo Y partindo do ponto $\mathrm{S}$, perpendicularmente ao eixo $\mathrm{X}^{27}$.

Para mensurar as alterações do ponto cervical do incisivo inferior, foi empregada a sobreposição parcial da mandíbula, delimitada pelo contorno interno da sínfise mandibular, contorno do canal

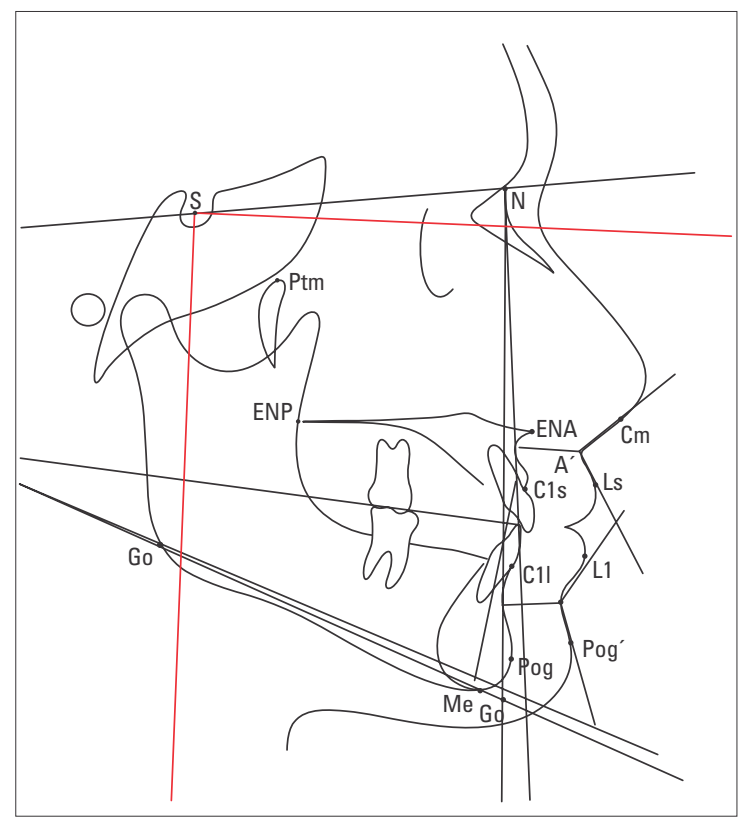

FIGURA 1 - Pontos, linhas e planos de referência. mandibular e borda inferior do corpo mandibular. As referências cartesianas também foram baseadas em uma linha traçada 7 graus abaixo da linha SN, bem como o eixo Y partindo do ponto S, perpendicularmente ao eixo $\mathrm{X}^{27}$.

A partir destas coordenadas foi mensurada, em milímetros, a movimentação dos incisivos superiores e inferiores (o sinal negativo foi usado quando houve retração e o positivo quando houve protrusão). Também foi analisado o comportamento vertical dentário, sendo que o movimento de intrusão foi classificado com o sinal negativo e o movimento de extrusão com o sinal positivo.

\section{Avaliação dos componentes esqueléticos}

As seguintes medidas foram utilizadas: a) componente maxilar: SNA; b) componente mandibular: SNB; c) relação maxilomandibular: ANB e WITS; d) relação vertical: SN.GoGn, SN.GoMe e AFAI (ENA-Me); e) componente tegumentar: ângulo nasolabial (ANL), ângulo mentolabial (AML), espessura do lábio superior e inferior (A-A', B-B'); f) componente dentário: ClS-X, ClSY e ClI-X,ClI-Y, e g) relação vertical e horizontal interincisivos: overjet e overbite.

\section{Análise estatística}

O tratamento estatístico foi executado pelo software Sigma Stat. (Jandel Scientific, Califórnia, USA). Segundo teste de normalidade e igualdade de variâncias, a indução foi realizada por meio do teste $t$ de Student pareado, por se tratar de comparações iniciais e finais do mesmo grupo. O nível de significância adotado foi o de $\mathrm{p}<0,05$.

\section{Erro do método}

Para avaliação do erro metodológico intra-examinador, selecionou-se aleatoriamente 20 telerradiografias da amostra, sendo que o examinador traçou os cefalogramas das mesmas duas vezes consecutivamente, com intervalo de 15 dias entre um e outro. A diferença entre a primeira e a segunda medição de cada variável resultou numa 
tabela montada no programa Excel para posteriores cálculos dos erros metodológicos.

O erro casual foi obtido com a aplicação da fórmula matemática proposta por Dahlberg. Os erros casuais maiores que 1,5 graus ou $1,0 \mathrm{~mm}$ foram considerados significantes.

\section{RESULTADOS}

A tabela 1 apresenta as médias das idades iniciais, finais e tempo de tratamento. Os testes de Dahlberg e t de Student para os erros do método demonstraram fidelidade das medidas, não apresentando nenhuma variável com imprecisão significante, com exceção da grandeza cefalométrica AFAI (ENA-Me), que apresentou um erro de $1 \mathrm{~mm}$ entre as duas mensurações.

A tabela 2 apresenta a comparação entre as médias das medidas no início e no final do tratamento ortodôntico.

A tabela 3 apresenta as médias de alterações de posição dos pontos cervicais dos incisivos superiores e inferiores (mediante o uso de sobreposições parciais), tanto no sentido horizontal quanto vertical (ClSX, ClIX, ClSY e ClIY).

Observa-se que os incisivos superiores foram retruídos, em média, $3,40 \mathrm{~mm}$, com referência ao ponto cervical, e os inferiores foram retruídos, em média, 1,83mm. Quanto ao movimento vertical, nota-se que os incisivos superiores extruíram, em média, $1,28 \mathrm{~mm}$ e os inferiores $1,12 \mathrm{~mm}$.

Tabela 1 - Média das idades iniciais, finais e tempo médio de tratamento total.

\begin{tabular}{cccc}
\hline $\mathbf{n}^{\text {0 }}$ pacientes & $\begin{array}{c}\text { idade } \\
\text { inicial }\end{array}$ & idade final & tempo tratamento \\
\hline 30 & $12 \mathrm{a} 04 \mathrm{~m}$ & $15 \mathrm{a} 5 \mathrm{~m}$ & 3a $1 \mathrm{~m}$ \\
\hline
\end{tabular}

Tabela 2 - Comparação entre as médias das medidas no início e no final do tratamento ortodôntico e teste t.

\begin{tabular}{|c|c|c|c|c|c|c|}
\hline medidas cefalométricas & \multicolumn{2}{|c|}{ inicial } & \multicolumn{2}{|c|}{ final } & alteração T2-T1 & $\mathbf{p}$ \\
\hline SNA (graus) & 84,93 & 4,28 & 83,18 & 4,79 & $-1,75$ & $0,03^{*}$ \\
\hline SNB (graus) & 79,15 & 4,68 & 78,97 & 4,79 & $-0,18$ & 0,76 \\
\hline ANB (graus) & 5,72 & 2,15 & 4,23 & 2,04 & $-1,49$ & $0,00^{*}$ \\
\hline SN.GoMe (graus) & 35,62 & 5,16 & 34,51 & 8,16 & $-1,11$ & 0,33 \\
\hline AFAI (mm) & 70,83 & 4,84 & 75,68 & 5,86 & 4,85 & $0,00^{*}$ \\
\hline ANL (graus) & 95,68 & 14,38 & 105,48 & 12,44 & 9,8 & $0,00^{*}$ \\
\hline Overjet (mm) & 4,23 & 2,51 & 1,07 & 0,67 & $-3,16$ & $0,00^{*}$ \\
\hline Overbite (mm) & 2,70 & 1,81 & 2,43 & 0,65 & $-0,27$ & 0,39 \\
\hline
\end{tabular}

* Estatisticamente significante ao nível de $\mathrm{p}<0,05$. 
Tabela 3 - Médias e desvios-padrão das alterações dos pontos cervicais dos incisivos superiores e inferiores.

\begin{tabular}{lllll}
\hline & C1SX $(\mathrm{mm})$ & C1SY $(\mathrm{mm})$ & C1IX $(\mathrm{mm})$ & C1IY $(\mathrm{mm})$ \\
\hline $\mathbf{X}$ & $-3,40$ & $+1,28$ & $-1,83$ & $+1,12$ \\
d.p. & 1,99 & 2,55 & 1,56 & 2,42 \\
\hline
\end{tabular}

COORDENADA $\mathrm{X}$ : valores positivos = protrusão, valores negativos $=$ retrusão

COORDENADA Y: valores positivos = extrusão, valores negativos $=$ intrusão

\section{DISCUSSÃO}

O presente estudo prospectivo objetivou avaliar cefalometricamente as alterações dentoesqueléticas e do perfil facial em 30 jovens tratados com extração dos 4 primeiros pré-molares e mecânica fixa Straight-wire.

Com o passar dos anos, o tratamento ortodôntico com extrações continua sendo motivo de debates e opiniões controversas. Numa certa fase, a polêmica refletiu sobre qual o melhor tratamento a ser adotado perante a estabilidade pós-tratamento: extracionista ou não extracionista? Autores como Tweed foram dogmáticos em afirmar que o tratamento ortodôntico teria maior estabilidade com exodontia de pré-molares, na grande maioria dos casos, porém tais ideais confrontaram com os ideais de Angle, idealizador de um conjunto harmonioso mantendo todos os dentes no arco dentário. Atualmente, sabe-se que a alteração da inclinação dos incisivos inferiores durante o tratamento ortodôntico, assim como a permanência ou não dos pré-molares na cavidade bucal, não resulta em casos mais estáveis no período pós-tratamento $0^{3,5}$.

Outros estudos ${ }^{19,21,24,27,30}$ conduziram o debate para obter respostas quanto ao impacto das extrações sobre a estética facial, interferindo sobre a questão da retração do perfil facial e do "abandeijamento" do mesmo.

A Ortodontia contemporânea tem acompanhado as tendências e costumes da época, aliando função, fonética, deglutição e estética e objetivando tais conceitos como ideais de um tratamento ortodôntico corretamente planejado e executado.
É sabido que o tratamento ortodôntico com exodontias produz alterações sagitais, verticais e transversais. Entretanto, seriam estas alterações, principalmente as do perfil tegumentar, advindas da mecânica ortodôntica ou oriundas do crescimento, desenvolvimento e "envelhecimento" normal do esqueleto e tecidos moles da face? Para responder a este questionamento procurou-se averiguar, por meio de telerradiografias, os efeitos dentoesqueléticos e do perfil facial oriundos da extração de pré-molares. Como não foi possivel a utilização de um grupo controle, procurou-se comparar as alterações cefalométricas dos jovens da amostra com os valores encontrados no Atlas de Crescimento Craniofacial ${ }^{22}$.

No presente trabalho, o valor do ângulo SNA no final do tratamento apresentou uma diminuição estaticamente significante, sendo este resultado semelhante aos encontrados ${ }^{15,24,28}$. Esta diminuição média de $1,7^{\circ}$ pode ser explicada, pois o tratamento foi realizado com extração de quatro primeiros pré-molares, conseqüentemente, parece ter havido uma mudança no ponto A para posterior, promovida pela retração dos incisivos superiores. Segundo o Atlas de Crescimento Craniofacial $^{22}$, que acompanhou longitudinalmente jovens brasileiros, leucodermas, sem tratamento ortodôntico, observou-se que, dos 13 aos 16 anos, o ângulo SNA apresentou um incremento médio de $0,4^{\circ}$. Deste modo, a diminuição deste ângulo parece ter sido gerada pela movimentação dos incisivos superiores para posterior.

A posição sagital da mandíbula, avaliada pelo ângulo SNB, no pós-tratamento não demonstrou diferença estaticamente significante quando comparada à média inicial, diminuindo $0,1^{\circ}$, o que por sua vez corrobora com alguns autores ${ }^{15}$ que avaliaram o efeito da extração sobre a mandíbula. Discordando deste resultado, o Atlas de Crescimento Craniofacial ${ }^{22}$ demonstrou que houve um incremento médio do ângulo SNB de 1,4 $4^{\circ}$. Esta diferença de resultados parece estar relacionada ao aumento da altura facial anterior que ocorreu 
nos jovens da presente amostra tratados com extração, que propiciou um giro mandibular no sentido horário.

A significativa diminuição das grandezas ANB e WITS, verificada para esta amostra, denota que houve melhora na relação sagital maxilomandibular de Classe II dos pacientes estudados, corroborando com a literatura pertinente ${ }^{15,24}$. Segundo o Atlas de Crescimento Craniofacial ${ }^{22}$, o ângulo ANB apresentou uma diminuição média de $0,9^{\circ}$, para jovens de 13 aos 16 anos sem tratamento ortodôntico. Nesta pesquisa, a diminuição do ângulo ANB foi da ordem de $1,4^{\circ}$. Já a medida linear WITS apresentou diminuição média de $1,7 \mathrm{~mm}$. Este resultado demonstra que o tratamento ortodôntico promoveu alterações dentoalveolares nos incisivos superiores e inferiores, que reduziram o overjet inicial do grupo estudado. Considerando que o crescimento craniofacial normal contribui com a diminuição de 1 grau dos 13 aos 16 anos de idade, a diminuição de 0,5 graus pode ser atribuída aos efeitos dentoalveolares da movimentação dos incisivos após a extração.

O padrão de crescimento mandibular, mensurado pelos ângulos SN.GoMe e SN.GoGn, não demonstrou alteração significante com o tratamento de extrações, fato este concordante com a literatura pertinente ${ }^{5,14,17,20}$. A altura facial ântero-inferior (AFAI) demonstrou um aumento estatisticamente significante, da fase pré-tratamento para a fase pós-tratamento, de $4,8 \mathrm{~mm}$, concordando com estudos prévios ${ }^{12,17}$.

$\mathrm{O}$ efeito do crescimento na dimensão vertical foi notório, demonstrando um deslocamento mandibular para baixo, o que refletiu na altura facial, já que a maioria dos pacientes deste estudo estava em um período de crescimento. Segundo o Atlas de Crescimento Craniofacial ${ }^{22}$, o aumento médio da AFAI em pacientes não tratados ortodonticamente é de $4,3 \mathrm{~mm}$ dos 13 aos 16 anos. $\mathrm{O}$ resultado desta pesquisa demonstrou um aumento médio similar ao verificado em jovens que não receberam tratamento, denotando que a extração de primeiros pré-molares não influenciou negativamente o aspecto vertical dos pacientes da presente amostra.

A posição horizontal e vertical dos incisivos superiores foi avaliada pelo deslocamento dos pontos $\mathrm{C} 1$ Sx e ClSy em relação às coordenadas $\mathrm{X}$ e $\mathrm{Y}$.

Ao final do tratamento, observou-se uma clara retração dos incisivos superiores ${ }^{5,12,24}$. Em média, os incisivos superiores retraíram $3,4 \mathrm{~mm}$ e extruíram $1,2 \mathrm{~mm}$, fato corroborado por outros autores ${ }^{4,29}$.

O apinhamento dentário apresenta influência direta nos casos estudados com extrações de pré-molares, pois quanto maior a quantidade de apinhamento menor será a quantidade de retração dos incisivos.

A posição dos incisivos inferiores foi avaliada pelo deslocamento dos pontos ClIx e Clly em relação às coordenadas X e Y. Observou-se uma retração média de $1,8 \mathrm{~mm}$ dos incisivos inferiores e extrusão de $1,1 \mathrm{~mm}$, coincidente com estudos previamente realizados ${ }^{13,16,19,23}$. A retração dos dentes inferiores obteve a mesma magnitude destes estudos, devido à ausência de ancoragem inferior, levando a um maior deslocamento mesial dos molares inferiores.

As alterações no perfil tegumentar parecem estar relacionadas ao posicionamento dentoalveolar obtido durante a mecânica ortodôntica. $\mathrm{O}$ ângulo nasolabial sofreu alteração estatiscamente significante, tornando-se mais obtuso em $9,8^{\circ}$. $\mathrm{O}$ fator de maior responsabilidade foi a retração dos incisivos superiores. No presente estudo, a retração média dos incisivos superiores foi de $3,4 \mathrm{~mm}$ para uma abertura de $9,8^{\circ}$ do ângulo nasolabial, levando a uma proporção de $1 \mathrm{~mm}: 2,8$ graus. As variações nas respostas de tecidos moles são muito extensas e difíceis de serem previstas ou correlacionadas completamente às da movimentação dentária. A literatura apresenta vários estudos $^{2,6,8,18,29}$ que analisaram as alterações do posicionamento dentário e suas conseqüências no perfil facial. 
Ramos $^{27}$ encontrou uma retração média de $4,56 \mathrm{~mm}$ dos incisivos superiores com uma alteração de $4^{\circ}$ no ângulo nasolabial. Por outro lado, Lo e Hunter ${ }^{21}$ encontraram uma correlação onde cada $1 \mathrm{~mm}$ de retração dos incisivos superiores aumenta $1,63^{\circ}$ o ângulo nasolabial, levando a uma correlação de 0,77 . Verificaram ainda que os casos com pequena retração respondem na mesma proporção $\left(1,63^{\circ}: 1 \mathrm{~mm}\right)$ que os casos com grande retração.

Os resultados cefalométricos apresentados em nossa pesquisa comprovaram existir uma íntima relação entre as alterações que ocorrem nos dentes e, conseqüentemente, no perfil facial tegumentar.

O ângulo mentolabial (AML) não sofreu alterações estaticamente significantes, diminuindo apenas $0,07^{\circ}$ pós-retração dos incisivos inferiores, podendo também ser justificadas pela grande perda de ancoragem póstero-inferior. A espessura do lábio superior foi medida pela grandeza cefalométrica $\mathrm{A}-\mathrm{A}^{\prime}$, onde se observou um aumento não significativo entre as fases pré e pós-tratamento ortodôntico. Subjetivamente, a retração do lábio superior melhorou a estética facial ${ }^{2,8,25,29}$. O lábio inferior (B-B') não sofreu alteração significativa do início para o final do tratamento.

O overjet apresentou uma diminuição significante de $3,1 \mathrm{~mm}$, melhorando conseqüentemente a relação interincisivos. O overbite apresentou uma redução média não significante de $0,2 \mathrm{~mm}$.

\section{CONSIDERAÇÕES CLÍNICAS}

Perante os resultados obtidos, conclui-se que a decisão de exodontia de quatro primeiros prémolares, em pacientes com má oclusão Classe II, $1^{\text {a }}$ divisão, baseada em critérios adequados para o diagnóstico, parece não ter efeito desfavorável sobre o perfil facial, desde que bem indicada e sendo levada em consideração a quantidade de apinhamento, o padrão facial, a espessura e tonicidade dos lábios ${ }^{5}$. Observou-se que as alterações no perfil facial são decorrentes, também, da retração dos incisivos. Os resultados apóiam a teoria de que a quantidade de apinhamento, o controle da mecânica e da ancoragem e uma análise facial criteriosa podem decidir sobre o plano de tratamento a ser seguido.

\section{CONCLUSÕES}

Baseado nos resultados obtidos e na metodologia utilizada, julga-se lícito concluir que:

- O ponto A sofreu pequena alteração devido à retração dos incisivos superiores, discriminada pela diminuição média do SNA (1,7 graus).

- Houve melhora na relação sagital maxilomandibular, demonstrada pela diminuição do WITS e ANB.

- Não houve diferenças estatisticamente significantes para as grandezas cefalométricas SN.GoGn e SN.GoMe; embora a AFAI (ENA-Me) tenha aumentado, em decorrência da extrusão compensatória dos molares durante a retração.

- Houve retração média dos incisivos superiores de $3,4 \mathrm{~mm}$ e dos inferiores de $1,8 \mathrm{~mm}$.

- Houve aumento significante no ângulo nasolabial pós-tratamento ortodôntico, sendo uma modificação média de 2,8 graus para cada milímetro de retração dos incisivos superiores, embora tenha havido grande variabilidade levando a confirmar a pouca previsibilidade de posicionamento dos lábios. 


\title{
Dentoskeletal and soft tissue profile changes after orthodontic treatment with first premolars extractions
}

\begin{abstract}
Objective: the purpose of this prospective study was to cephalometrically analyze the dentoalveolar and soft tissue changes after the orthodontic treatment followed by the extraction of four premolars. Material and methods: the sample was comprised by 30 Class II division 1 patients with mean initial age of 12 years and 4 months. Two lateral cephalograms were obtained from each patient at the beginning and at the end of the treatment. The variables analyzed were the nasalabial changes and upper and lower incisors changes in relation to a vertical and horizontal $x$ and y reference lines. Results: upper and lower incisors retraction was 3.4 and $1.8 \mathrm{~mm}$, respectively. The SNA angle was decresead by 1.7 degrees followed by a retraction of point $A$ mainly due to the upper incisor retraction. There was a significant decrease of the Wits and ANB variables. There was an increase in the lower anterior facial height. Upper incisor retraction was followed by an increase in the nasolabial angle (ratio 1:2.8 degrees). However, a wide range of individual variability was found. Conclusions: the present study did not support the simple expectation that treatment with extractions of four premolars will result in a dished in face. It appeared that facial changes were more related to a normal facial growth, the amount of incisor retraction and the anchorage control during the upper and lower incisor.
\end{abstract}

Key words: Pre-molars extractions. Facial profile. Orthodontic treatment.

\section{REFERÊNCIAS}

1. ANGLE, E. H. Treatment of malocclusion of the teeth. 7th ed. Philadelphia: S. S. White Dental Manufacturing, 1907. p. 60-87

2. ASSUNÇÃO, Z. L. V. et al. Incisor retraction and profile changes in adult patients. Int. J. Adult Orthod. Orthognath. Surg. Lombard, v. 9, no. 1, p. 31-36, 1994.

3. BASCIFITI, F. A. Effect of extraction and nonextraction treatment on Class I and Class II subjects. Angle Orthod., Appleton, v. 73, no. 1, p. 12-18, 2003.

4. BIMLER, H. P. Analisis cefalometrico como fundamento da estomatopedia. Buenos Aires: Mundi, 1977. Apud SIMÕES, W.A. Ortopedia funcional dos maxilares. São Paulo: Ed. Santos, 1985. p. 31-38.

5. BISHARA, S. E. et al. Dentofacial and soft tissue changes in Class II, division 1 cases treated with and without extractions. Amer. J. Orthod. Dentofacial Orthop., St. Louis, v. 107 p. 28-37, Jan. 1995.

6. BOWMAN, S. J. Estética facial na Ortodontia: mais que um trabalho bucal. JADA, Brasil, v. 2, p. 5-13, 1999.

7. BOWMAN, S. J.; JOHNSTON JR., L. E. The esthetic impact of extraction and nonextraction treatment on Caucasian patients. Angle Orthod., Appleton, v. 70, no. 1, p. 3-10, 2000.

8. BRAVO, L. A. et al. Comparison of the changes in facial profile after orthodontic treatment, with and without extractions. B. J. Orthod., Oxford, v. 24, no. 1, p. 25-34, Feb. 1997.

9. BUCHIN, I. D. An appraisal of the effect of the edgewise arch appliance in modifying the dentofacial profile. Am. J. Orthod. St. Louis. v. 43, no. 11, p. 801-818, Nov. 1957.

10. CARVALHO, A. B.; OliveirA. A. G.: OLIVEIRA, R. A. Estudo da proporção de retração dos lábios em relação à retração dos incisivos em pacientes com maloclusão Classe II, divisão 1 de Angle tratados com a técnica do arco de canto e extração de pré-molares. J. Bras. Ortodon. Ortop. Facial, Curitiba, v. 4 , n. 24, p. $476-485,1999$
11. CASE, O. S. A practical treatise of the technics and principies of dental orthopedia and correction of cleft palate. 2 nd ed. Chicago: C.S.Case, 1921

12. CUSIMANO, C.; McLAUDHILIN, R. P.; ZERNICK, J. H. Effects of four first bicuspid extractions on facial height in High-Angle cases. J. Clin. Orthod., Boulder, v. 27, p. 594-598, Nov. 1993.

13. DOWNS, W. B. Analysis of the dentofacial profile. Angle Orthod., Appleton, v. 26, no. 4, p. 191-212, Oct. 1956.

14. HAYASAKI, S. M. Estudo cefalométrico das alterações das alturas faciais anterior e posterior em pacientes nipo-brasileiros com más-oclusões de Classe I e Classe II, $1^{\text {a }}$ divisão de Angle, tratados ortodonticamente. 2002. Dissertação (Mestrado)-Faculdade de Odontologia de Bauru, Universidade de São Paulo, Bauru, 2002

15. HOLDAWAY, R. A. Changes on relationship of points $A$ and $B$ during orthodontic treatment. Am. J. Orthod., London, v. 13, no. 4, p. 209-220, Oct. 1956.

16. KANASHIRO, N. S.; TAKAHASHI, I. Perfil facial. 1990. Trabalho de Conclusão de Curso (Especialização)-Universidade Estadual de Londrina, Londrina, 1990.

17. KOCADERELI, I. The effect of first premolar extraction on vertical dimension. Am. J. Orthod. Dentofacial Orthop., St. Louis, v. 116, no. 1, p. 41-45, July 1999.

18. La MASTRA, S. J. Relationships between changes in skeletal and integumental points $A$ and $B$ following orthodontic treatment. Am. J. Orthod., St. Louis, v. 79, no. 4, p. 416-423, Apr. 1981.

19. LINDQUIST, J. The lower incisor its influence on treatment and esthetics. Am. J. Orthod., St. Louis, v. 44, no. 2, p. 112-140, Feb. 1958.

20. LINN, K. A. The comparative study of first and second premolar extraction treatment and their effects upon vertical facial development. 1992. (Master's Thesis)-Department of Orthodontics, University of Southern California, Los Angeles, 1992 
21. LO, F. D.; HUNTER, W. S. Changes in nasolabial angle related to maxillary incisor retraction. Am. J. Orthod., St. Louis, v. 82, no. 5, p. 384-391, Nov. 1982

22. MARTINS, D. R. et al. Atlas de crescimento crânio-facial. São Paulo: Ed. Santos, 1998.

23. MARTINS, D. R. Estudo comparativo dos valores cefalométricos das análises de Downs, Tweed, Steiner e Alabama, com os de adolescentes brasileiros, leucodermas, de origem mediterrânea. 1979. 141 f. Tese (Livre-Docente)-Faculdade de Odontologia de Bauru, Universidade de São Paulo, Bauru, 1979.

24. NAHAS, A. C. R. Avaliação da estabilidade esquelética e dentária das medidas cefalométricas após cinco anos, em pacientes com ângulo ANB inicial maior que $4^{\circ}$, tratados ortodonticamente com extrações dos quatro primeiros pré-molares. 2001. Dissertação (Mestrado)-Faculdade de Odontologia de Bauru, Universidade de São Paulo, Bauru, 2001.

25. NAKAMA, R. K. Avaliação cefalométrica da retração dos dentes incisivos superiores e inferiores com arco base de Ricketts e sua relação com o perfil do tecido mole. Ortodontia
Paranaense, Curitiba, v. 14, n. 1, p. 11-22, jan./jun. 1993.

26. PHELPS, A. E. Facial esthetics and the Tweed technique. J. Charles H. Tweed Int. Found., Tucson, v. 16, p. 28-38, Apr. 1988

27. RAMOS, L. A. Alterações do perfil tegumentar de pacientes com má oclusão Classe II divisão 1, com e sem selamento labial, tratados com extrações dos primeiros pré-molares superiores: estudo com implantes metálicos. 2002. Tese (Doutorado)-UNESP, Faculdade de Odontologia de Araraquara, Araraquara, 2002

28. RICKETTS, R. M. The influence of orthodontic treatment on facial growth and development. Angle Orthod., Appleton, v. 3, no. 3, p. 103-133, July 1960.

29. SAELENS, N. A.; DE SMITH, A. A. Therapeutic changes in extraction versus non-extraction orthodontic treatment. Eur. J. Orthod., Oxford, v. 20, no. 3, p. 225-236, June 1998

30. ZIERHUT, E. C. et al. Long-term profile changes associated with successfully treated extraction and nonextraction Class II division 1 malocclusion. Angle Orthod., Appleton, v. 70, no. 3, p. $208-219,2000$
Endereço para correspondência

Giovani Fidelis de Oliveira

SEPS 710-910 Sala 312 - Centro Clínico Via Brasi

CEP: 70.390-108 - Brasília / DF

E-mail: gfidelis@globo.com 